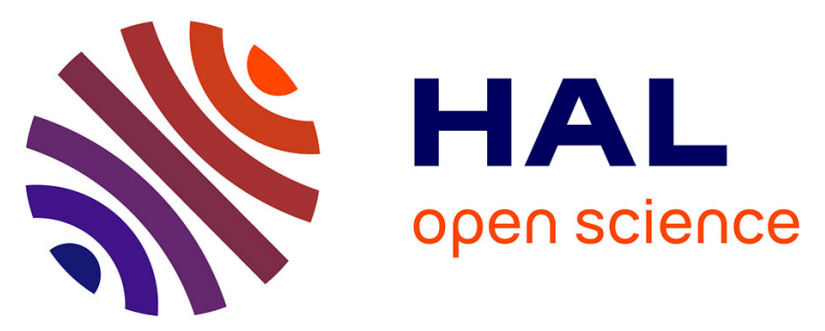

\title{
Phospho-GlcNAc modulation of slow MLC2 during soleus atrophy through a multienzymatic and sarcomeric complex.
}

Caroline Cieniewski-Bernard, Erwan Dupont, Elodie Richard, Bruno Bastide

\section{- To cite this version:}

Caroline Cieniewski-Bernard, Erwan Dupont, Elodie Richard, Bruno Bastide. Phospho-GlcNAc modulation of slow MLC2 during soleus atrophy through a multienzymatic and sarcomeric complex.. Pflügers Archiv European Journal of Physiology, 2014, 466, pp.2139-2151. 10.1007/s00424-014-1453y . hal-02539468v2

\section{HAL Id: hal-02539468 \\ https://hal.univ-lille.fr/hal-02539468v2}

Submitted on 16 Apr 2020

HAL is a multi-disciplinary open access archive for the deposit and dissemination of scientific research documents, whether they are published or not. The documents may come from teaching and research institutions in France or abroad, or from public or private research centers.
L'archive ouverte pluridisciplinaire HAL, est destinée au dépôt et à la diffusion de documents scientifiques de niveau recherche, publiés ou non, émanant des établissements d'enseignement et de recherche français ou étrangers, des laboratoires publics ou privés. 


\title{
Phospho-GIcNAc modulation of slow MLC2 \\ during soleus atrophy through a \\ multienzymatic and sarcomeric complex
}

\begin{abstract}
Caroline CIENIEWSKI-BERNARD**\$\#, Erwan DUPONT*», Elodie RICHARD**, and Bruno BASTIDE* ${ }^{* \dagger}$
\end{abstract}

*Université Lille Nord de France, Lille, France

$\dagger$ †A4488, Université de Lille 1, Villeneuve d'Ascq, France

$\$$ BICeL - IFR147 (BioImaging Center of Lille), Université de Lille 1, Villeneuve d'Ascq, France

$\S$ These authors have equally contributed to this work

${ }^{\#}$ To whom correspondence should be address:

Dr Caroline Cieniewski-Bernard, Laboratoire Activité Physique, Muscle et Santé, EA4488, IFR114, Université de Lille 1, 59655 Villeneuve d'Ascq Cedex, France, Tel : +33 320434089; Fax : +33 320436888; E-mail address: caroline.cieniewski-bernard@univ-lille1.fr 


\section{ABSTRACT}

Although calcium is the major regulator of excitation-contraction coupling, myofilament function can also be modulated through post-translational modifications. In particular phosphorylation and O-GlcNAcylation are key modulators of calcium activation parameters. Among the regulatory proteins of skeletal muscle contraction, the myosin light chain 2 (MLC2) can undergo both types of post-translational modification. During aging or physical inactivity, the phosphorylation status of the slow isoform of MLC2 (sMLC2) does not correlate with calcium sensitivity, suggesting that the O-GlcNAcylation might modulate sMLC2 activity. To increase understanding of the contractile dysfunction associated with muscle atrophy, we studied the phosphorylation/ O-GlcNAcylation interplay on the sMLC2.

We demonstrate a two-fold decrease of O-GlcNAcylation level on sMLC2 in a rat model of skeletal muscle atrophy (hindlimb unloading), while phosphorylation increased. Both post-translational modifications were mutually exclusive. Their interplay reversed during reloading. The expression of enzymes involved in the phosphorylation and O-GlcNAcylation interplay on sMLC2 was modified on whole protein pattern as well as on myofilament, and was loaddependent. All enzymes were colocalized on the contractile apparatus. Finally, we describe a multienzymatic complex which might finely modulate the phosphorylation/ dephosphorylation and O-GlcNAcylation/de-O-GlcNAcylation of sMLC2 that could be involved in the contractile dysfunction of atrophied muscle. Importantly, this complex was localized at the Z-disk, a nodal point of signalling in skeletal muscle.

\section{$\underline{\text { KEYWORDS }}$}

Skeletal muscle atrophy, hindlimb unloading, O-GlcNAcylation, phosphorylation, regulatory myosin light chain, multienzymatic complex 


\section{INTRODUCTION}

Numerous cellular processes are regulated through post-translational modifications. Among them, O-N-acetyl-glucosaminylation, termed O-GlcNAcylation, is an atypical glycosylation. Inducible, reversible and highly dynamic, O-GlcNAcylation is more akin to phosphorylation than classical glycosylations. As such, the O-GlcNAcylation upsets the dogma of complex glycosylation since (i) the subcellular compartmentation is exquisitely nucleocytoplasmic [17], (ii) the monosaccharide linked to protein backbone is not elongated [46], and (iii) the process is able to respond rapidly to extracellular stimuli (for reviews, see $[10,18]$ ).

The addition and removal of GlcNAc moieties on the proteins are mediated by the concerted action of two conserved and antagonist enzymes. The first one is uridine diphospho- $\mathrm{N}-$ acetylglucosamine: peptide $\beta$-N-acetylglucosaminyl-transferase (or OGT), which transfers the monosaccharide from the donor UDP-GlcNAc to the serine or threonine hydroxyl group of a protein through a beta linkage $[15,16]$. The activity, specificity and cellular localization of OGT are ensured by targeting proteins which are transiently associated with OGT through $\mathrm{N}$-terminal tetratricopeptide repeats $[4,5,23]$. The second one is the $\beta$-N-acetylglucosaminidase (or OGA, also termed MGEA5); this only known nuclear and cytosolic glycosidase is responsible for the GlcNAc removal on all OGlcNAcylated proteins, with strict substrate specificity toward $\beta$-linked GlcNAc [11, 14, 47]. MGEA5/OGA is a bifunctional enzyme, constituted by a catalytic domain and a histone acetyltransferase domain. The OGA is also associated with other proteins such as calcineurin or heat shock proteins among others [47]. Surprisingly, an unusual association of the two opposing OGA-OGT has been described, in which a single O-GlcNAczyme complex was formed [49].

The O-GlcNAcylation is crucial to regulate several if not all key cellular processes; in particular, O-GlcNAcylation was shown to be involved in cellular stress response, transcription, translation, modulation of signalling pathways, protein degradation and so on (for review, see [19]). Thus, a dysregulation of the O-GlcNAcylation process was closely associated with the aetiology of several diseases such as type II diabetes mellitus, cancer or neurodegenerative disorders [22, 26, 27]. OGlcNAcylation is also involved in several heart $[28,30]$ or skeletal muscle $[9,21,34]$ diseases.

In healthy muscle, there is a growing body of evidence that strongly support the role of OGlcNAcylation in skeletal muscle physiology, particularly in the fine regulation of the contractile activity. Indeed, among structural and contractile proteins, key motor and regulatory proteins of the contractile apparatus are O-GlcNAcylated, including myosin heavy chains (MHC), actin, tropomyosin, $\mathrm{T}$ and I troponins, as well as essential and regulatory myosin light chains (MLC1 and MLC2 respectively) $[6,8,20]$. In view of the large panel of contractile proteins bearing O-GlcNAc moieties, we have previously investigated the role of O-GlcNAcylation on calcium activation parameters. The disruption of protein-protein interactions depending of the O-GlcNAc moiety (through the incubation of skeletal skinned fibers in a free-GlcNAc solution) was associated with a decrease of calcium 
sensitivity [20]. In contrast, the increase of O-GlcNAcylation level on soleus muscle leads to the increase of calcium sensitivity [7]; interestingly, the only slow isoform presenting an increase of its O-GlcNAc level was the MLC2 (sMLC2), a regulatory contractile protein non-covalently associated with the headto-neck junction of MHC. The glycosylation/deglycosylation process involves the OGT/OGA enzymes respectively, even if the modulation of their activity toward MLC2 as well as their cellular localization on skeletal muscle fibers remains unknown to date. In soleus, sMLC2 is also termed phosphorylatable MLC as it could be phosphorylated on serine 14 by the myosin light chain kinase (MLCK or $\mathrm{Ca}^{2+} /$ calmodulin-dependent serine-threonine protein kinase) [1, 42]. The reversible mechanism is supported by protein phosphatase 1 (PP1), the major serine/threonine phosphatase in eukaryotes. The myosin phosphatase target 2 (MYPT2) corresponds to the regulatory subunit of myosin phosphatase which target PP1 to myosin [31]. The MLC2 phosphorylation results in the modulation of contractile properties through the enhancement of calcium sensitivity [24, 42, 45]. Taking into account the data provided by our team and others, it seems that MLC2 phosphorylation and/or O-GlcNAcylation could modulate its activity, and to a large extent the contractile mechanism of skeletal muscle. Although numerous data argue that MLC2 phosphorylation increases calcium sensitivity in skeletal muscle [24, $29,36,43,44]$, it has been demonstrated that aging or reduced physical activity resulting from hindlimb unloading (HU) leads to an increase of MLC2 phosphorylation whereas the calcium sensitivity decreases $[2,13]$. As a consequence, the decrease in calcium sensitivity occurring during $\mathrm{HU}$ could not result from phosphorylation variation, but rather may involve another type of regulation such as O-GlcNAcylation.

Our aim was to investigate the phosphorylation/O-GlcNAcylation interplay on the slow isoform of MLC2. As such, we measured the variation of O-GlcNAcylation level on the unphosphorylated and the phosphorylated forms of SMLC2 in a rat model of HU followed or not by a reloading period to mimic recovery. The variation of the expression of the enzymes implicated in the modulation of $\mathrm{O}$ GlcNAcylation and phosphorylation was also determined on the total soleus proteome as well as the myofilament proteins. We investigated the existence of a supra-molecular complex involving OGT, OGA, MLCK, PP1 and/or MYPT2 to explain the dynamic interplay between phosphorylation and OGlcNAcylation of sMLC2, and we also attempted to localize each enzyme along the contractile apparatus.

\section{MATERIALS AND METHODS}

\section{$\underline{\text { Animals }}$}

Thirty-five adult male Wistar rats were randomly divided into three groups: $\mathrm{C}$ (control animals); HU (14-days hindlimb unloading); R (recovery: 14-days hindlimb unloading followed by 14 days of reloading). Hindlimb unloading was performed as previously described [32, 33]. The animals were 
housed individually under temperature and light controlled conditions $\left(23^{\circ} \mathrm{C}, 12: 12 \mathrm{~h}\right.$ light-dark cycle); they were allowed free access to food and water, and daily consumption of rat chow and water was monitored. The day before the sacrifice, animals were fasted. Soleus muscles were quickly removed from the animals anesthetized with intraperitoneal injection of sodium pentobarbital $(60 \mathrm{mg} / \mathrm{kg})$. Muscles were weighted and immediately frozen in liquid nitrogen. For each animal, the right muscle was used for biochemical analysis, while the left one was frozen lengthwise in isopentane for immunofluorescence analysis. All muscles were stored at $-80^{\circ} \mathrm{C}$ until analysis.

\section{Proteins extraction}

Right muscles were powdered in a steel stain mortar, and resting material was stored at $-80^{\circ} \mathrm{C}$. Depending on the experiment, total proteins or myofilament proteins were extracted using RipA or NP40 buffers as described below.

\section{Total proteins extraction}

Muscle powders were resuspended in cold RipA (10 mM Tris/HCl, pH 7.4; $150 \mathrm{mM} \mathrm{NaCl;} 1$ mM EDTA; $1 \%$ TritonX-100; 0.5\% sodium deoxycholate; 0.1\% SDS) or in NP-40 (20 mM Tris base, pH 8.0; $150 \mathrm{mM} \mathrm{NaCl} ; 1 \%$ NP-40) buffers, containing anti-proteases (Complete EDTA-free, Roche Diagnostic), anti-phosphatases (Phos-Stop, Roche Diagnostic), and $50 \mu \mathrm{M}$ PUGNAc (O-(2-acetamido2-deoxy-D-glucopyranosilidene)amino-N-phenyl-carbamate, Sigma). Samples were sonicated (Ultrasonic Cell Disruptor) and homogenized with gentle agitation for $1 \mathrm{~h}$ at $4^{\circ} \mathrm{C}$. Samples were centrifuged at $13000 \mathrm{rpm}$ for $10 \mathrm{~min}$ at $4^{\circ} \mathrm{C}$. Protein estimation of supernatant was done using Bradford assay (Biorad).

\section{Myofilament proteins extraction}

Muscle powder was resuspended in a 6.5 mM EDTA solution, $\mathrm{pH} 7.0$, containing anti-proteases, anti-phosphatases and PUGNAc. Samples were sonicated, homogenized for $1 \mathrm{~h}$ at $4^{\circ} \mathrm{C}$ and then centrifuged at $13000 \mathrm{rpm}$ for $10 \mathrm{~min}$ at $4^{\circ} \mathrm{C}$. Pellets were washed twice with $50 \mathrm{mM} \mathrm{KCl}$. The final pellets were resuspended in RipA buffer containing anti-proteases, anti-phosphatases and PUGNAc. Protein estimation was performed according to Bradford assay.

\section{$\underline{\text { Electrophoresis }}$}

\section{SDS-PAGE}

Total or myofilament proteins were diluted in sample buffer $(50 \mathrm{mM}$ Tris/ $\mathrm{HCl}, \mathrm{pH} 6.8 ; 2 \%$ SDS; $10 \%$ glycerol; $5 \% \beta$-mercaptoethanol; $0.1 \%$ bromophenol blue), and boiled for $5 \mathrm{~min}$. Proteins were separated by SDS-PAGE on 7.5\% or 15\% acrylamide:bisacrylamide [37.5:1] gels (Mini Protean system, 
Biorad).

\section{Phos-tag affinity electrophoresis}

Samples were run on discontinuous SDS-PAGE gels (Mini Protean system, Biorad). The gel consisted of a stacking gel (4\% acrylamide:bis-acrylamide [29:1]) and a separating gel (12,5\% acrylamide:bisacrylamide [29:1], containing $100 \mu \mathrm{M} \mathrm{MnCl}_{2}$ and $20 \mu \mathrm{M}$ Phos-Tag ${ }^{\mathrm{TM}}$ acrylamide [PhosTag $^{\text {TM }}$ AAL-107, NARD Institute]). The current was initially $25 \mathrm{~mA} /$ gel, raised to $35 \mathrm{~mA} /$ gel once the samples had entered the resolving gel. After electrophoresis, gels were soaked for $15 \mathrm{~min}$ in transfer buffer as described just below, except that SDS was replaced by 1 mM EDTA. Then, gels were washed twice for $10 \mathrm{~min}$ in transfer buffer without EDTA and finally blotted on nitrocellulose membrane for 2 $\mathrm{h}$ at $200 \mathrm{~mA}$.

Phosphorylated and non-phosphorylated isoforms of MLC2 were assigned after enzymatic dephosphorylation of proteins using alkaline phosphatase treatment. Briefly, $50 \mu \mathrm{g}$ of proteins were diluted in $20 \mathrm{mM}$ Tris buffer, $\mathrm{pH}$ 8.0, added with anti-proteases. Twenty UI of alkaline phosphatase (Sigma) was added; enzymatic reaction was performed at $37^{\circ} \mathrm{C}$ for $4 \mathrm{~h}$.

\section{Western blot analysis}

After separation, proteins were transferred to $0.2 \mu \mathrm{m}$ nitrocellulose membranes (Hybond, GE Healthcare) using transfer buffer (20 mM Tris base; $150 \mathrm{mM}$ glycine; $20 \%$ methanol), added with $0.025 \%$ SDS for the transfer of high-molecular weight proteins. Proteins load and quality of transfer were verified by Ponceau staining. The blots were then subsequently washed in TBST (15 mM Tris/HCl, pH 7.6; $140 \mathrm{mM} \mathrm{NaCl} ; 0.05 \%$ Tween-20) and blocked in 5\% non-fat dry milk or BSA in TBST. Membranes were then blotted with primary antibody aga inst OGT, OGA, MLCK, PP1, MYPT2 and sMLC2 (Abcam) in blocking solution) for $2 \mathrm{~h}$ at room temperature (RT) or overnight $(\mathrm{o} / \mathrm{n})$ at $4{ }^{\circ} \mathrm{C}$. Membranes were washed $3 \times 10 \mathrm{~min}$ in TBST, and then incubated with HRP-labelled secondary antibodies in blocking solution for $2 \mathrm{~h}$ at RT followed by $5 \times 10$ min washes in TBST. All experimental procedures were optimized for each antibody. Detection was carried out using the ECL or ECL Plus Western blotting detection reagents (Perkin Elmer) and hyperfilms Biomax MR (GE Healthcare).

The densitometric analysis was performed using GS-800 Imaging densitometer and QuantityOne Software (Bio-Rad). The intensity of the bands of interest was presented as means \pm SEM. Significance of intergroup differences was examined using one-way ANOVA. Post hoc analysis was performed using Bonferroni's test. Differences were considered significant when $p<0.05$.

\section{Proteins enrichment}

\section{RL-2 immunoprecipitation}

Immunoprecipitation of O-GlcNAc bearing proteins were performed using the RL-2 antibody 
(Affinity BioReagents). To abrogate protein-protein interactions, $100 \mu \mathrm{g}$ of myofilament proteins were first incubated $1 \mathrm{~h}$ at $\mathrm{RT}$ in $6 \mathrm{M}$ guanidine chlorhydrate under agitation. Samples were then passed through Vivaspin (cut-off of $50 \mathrm{kDa}$, Sartorius Stedim). The non-retained fraction (corresponding so to proteins with molecular weight $<50 \mathrm{kDa}$ ) was then desalted on $3 \mathrm{kDa}$-Vivaspin and buffer-exchanged toward RipA buffer containing PUGNAc, anti-proteases and anti-phosphatases.

Samples were pre-cleared with protein G coupled on magnetic beads (Millipore). Non-retained samples were incubated with RL-2 (1/250e) $1 \mathrm{~h}$ at RT with gentle agitation, followed by $1 \mathrm{~h}$-incubation at RT with magnetic beads $(1: 5, \mathrm{v} / \mathrm{v})$. Beads were washed sequentially using RipA; RipA+0.5 M NaCl; RipA/TNE (TNE: $10 \mathrm{mM}$ Tris/HCl, pH 7.4; $150 \mathrm{mM} \mathrm{NaCl;} 1 \mathrm{mM}$ EDTA) (50:50, v/v), and the last one with TNE. Beads were finally resuspended in Laemmli buffer and boiled for $10 \mathrm{~min}$. The remaining soluble fractions, corresponding to O-GlcNAc bearing proteins, were analyzed using Phos-Tag acrylamide gel electrophoresis and western blot with anti-MLC2 antibody.

Negative experiments were performed on samples deglycosylated by 10 UI of $\beta$-N-acetylhexosaminidase (New England Biolabs) treatment prior to the immunoprecipitation protocol. Briefly, proteins were boiled in SDS 1\% and then diluted in citrate/phosphate buffer, $\mathrm{pH} 4.0$ added with Triton $\mathrm{X}-100$ (1\% final concentration). Enzymatic deglycosylation was performed o/n at $37^{\circ} \mathrm{C}$.

\section{Co-immunoprecipitation}

Co-immunoprecipitation (co-IP) experiments were performed on $500 \mu \mathrm{g}$ of total proteins extracted in NP-40 buffer. Antibodies directed against OGT, OGA, PP1, MYPT2, MLCK or sMLC2 (Abcam) were used for co-IP. Experiments were performed as described just above, except that proteins were diluted in NP-40 buffer containing PUGNAc, anti-proteases and anti-phosphatases. After preclearing, samples were incubated with primary antibody $(1 / 100 \mathrm{e})$ at $4{ }^{\circ} \mathrm{C}$ o/n with gentle agitation, and then for $2 \mathrm{~h}$ at $4^{\circ} \mathrm{C}$ with magnetic beads $(1: 5, \mathrm{v} / \mathrm{v})$. Beads were extensively washed four times with NP40 buffer, and finally resuspended in Laemmli buffer for $10 \mathrm{~min}$ boiling. Proteins were separated on 7.5-15\% acrylamide gel electrophoresis (20x20 cm gels, Biorad XL) and analysed by western blot. Antibodies directed against OGT, OGA, PP1, MYPT2, MLCK and SMLC2 were blotted for each co-IP.

\section{Affinity chromatographies for enrichment of phosphoproteins and/or O-GlcNAc proteins}

The enrichment of phosphoproteins was performed using the ProQ® Diamond Phosphoprotein enrichment kit (Molecular Probes) according to the manufacturers' recommendations. The procedure was applied on $1 \mathrm{mg}$ of myofilament proteins diluted in wash buffer included in the kit. Sample was first pre-cleared using $1 \mathrm{ml}$-bed column of agarose beads. Non-retained fraction was then passed through $1 \mathrm{ml}$-bed column of chromatographic resin; flow-through was recycled three times to ensure the better retention of phosphorylated proteins. After several washes, retained proteins were eluted from the column using the elution buffer supplied in the kit. Non-retained (NR) and eluted (E) fractions were desalted/concentrated or buffer-exchanged against WGA (Wheat Germ Agglutinin)-binding buffer (as 
described just below) using $3 \mathrm{kDa}-V i v a s p i n$. The NR and $\mathrm{E}$ fractions were submitted to a second round of chromatography on WGA-agarose as described just below, or the eluted fraction was directly analyzed using western blot against sMLC2.

The O-GlcNAcylated proteins enrichment was performed using WGA-agarose beads (Sigma). The procedure was applied on $1 \mathrm{mg}$ of myofilament proteins diluted in binding buffer $(25 \mathrm{mM}$ Tris/ $\mathrm{HCl}$, pH 7.8; $300 \mathrm{mM} \mathrm{NaCl} ; 5 \mathrm{mM} \mathrm{CaCl}_{2} ; 1 \mathrm{mM} \mathrm{MgCl}_{2}$ ). Sample was first pre-cleared using $1 \mathrm{ml}$-bed column of agarose beads. The NR fraction was then passed through $300 \mu$ l-bed column of WGA-agarose; flowthrough was recycled three times to ensure the better retention of O-GlcNAcylated proteins. Column was extensively washed with wash buffer ( $0.2 \%$ NP-40 in PBS), followed by a wash with Gal buffer (1 $\mathrm{M}$ galactose in wash buffer) and washed again with wash buffer. Retained proteins were finally eluted from the column using elution buffer (1 M N-acetyl-D-glucosamine in wash buffer). The NR and $\mathrm{E}$ fractions were desalted/concentrated or buffer-exchanged against the wash buffer of the ProQ® Diamond enrichment kit using $3 \mathrm{kDa}-$ Vivaspin. The NR and $\mathrm{E}$ fractions were submitted to a second round of chromatography on ProQ® Diamond column, or the eluted fraction was directly analyzed using western blot against sMLC2.

\section{$\underline{\text { Immunofluorescence analysis }}$}

Serial sections (10 $\mu \mathrm{m}$ thick) of isopentane-frozen soleus were cut longitudinally on Hyperfrost glass-slides and immediately fixed in $2 \%$ paraformaldehyde in $\mathrm{PBS}, \mathrm{o} / \mathrm{n}$ at $4{ }^{\circ} \mathrm{C}$ in a humidified chamber. Slides were washed in PBS until permeabilization in 0.2\% Triton X-100 in PBS (30 min, RT). Nonspecific sites were blocked with BSA $(0.2 \%$ in PBS) for $30 \mathrm{~min}$ at RT. Thereafter, the slides were incubated with the primary antibodies (Abcam) diluted in blocking solution for $2 \mathrm{~h}$ at RT. Antibodies directed against OGT, OGA, PP1, MYPT2 and MLCK were used for co-localization analysis of the enzymes with a marker of the Z-disk (i.e. actinin). Washes in PBS were followed by incubation ( $2 \mathrm{~h}$, RT) with secondary antibodies labelled with AlexaFluor488 or AlexaFluor555 (Molecular Probes). Double staining was performed to analyze co-localization of protein partners or the localization of enzymes along the contractile apparatus. Slides were extensively washed before mounting with VectaShield mounting medium (Vector Laboratories). As negative controls, primary antibodies were omitted. Slides were visualized by confocal microscopy (LSM780, Carl Zeiss MicroImaging GmbH); acquisitions were performed using Zen2010 software (Zeiss). The DIC (Differential Interference Contrast) and fluorescence images were acquired simultaneously on slides. DIC microscopy was performed with $488 \mathrm{~nm}$ laser and transmitted light detector (T-PMT). Image analysis was done on around ten $80 \mathrm{x} 80 \mu \mathrm{m}$ images acquired on different muscles from two independent experiments. Images were analyzed using ImageJ software (MacBiophotonics) with Colocalization Analysis plugin. Manders' and Pearson's coefficients were determined to get the degree of overlap between two channels in microscopy images. 


\section{RESULTS}

\section{Slow MLC2 was modulated through a balance between phosphorylation and O-GlcNAcylation}

To quantify the variation of O-GlcNAcylation on sMLC2 according to its nonphosphorylated/phosphorylated states, we used the phosphate affinity SDS-PAGE. The O-GlcNAc bearing proteins were first immunoprecipitated using the RL-2 antibody and thereafter separated on Phos-tag ${ }^{\text {TM }}$ acrylamide gel. The acrylamide-pendant Phos-tag ${ }^{\mathrm{TM}}$, incorporated within gel matrix, retards phosphoproteins during electrophoresis, thus allowing the separation of the phosphorylated species from their un-phosphorylated form according to their number of phosphate moieties. So, each form of the protein (i.e. the unphosphorylated, and mono-, bis-, or more phosphorylated forms) can be easily identified and quantified after western. This strategy permitted to quantify the variation of $\mathrm{O}$ GlcNAcylation on each phosphorylation state of sMLC2. The same strategy was applied without preliminary immunoprecipitation in order to quantify the variation of phosphorylation on sMLC2 during HU and after reloading (figure 1).

As presented in Fig.1a, Phos-tag ${ }^{\mathrm{TM}}$ acrylamide retained the phosphorylated sMLC2 compared with the unphosphorylated (and so the non-retained) form of the regulatory protein. No additional bands corresponding to multi-phosphorylated forms of sMLC2 were detected, even when hyperfilm was overexposed. The effective nature of the phosphorylated form was confirmed using alkaline phosphatase treatment, which led to the disappearance of retained form toward only one band corresponding to the unphosphorylated form of the protein (data not shown). We expressed the variation of phosphorylation on sMLC2 as the ratio between the intensities of the phosphorylated band and total sMLC2. It is noteworthy that sMLC2 expression remained similar between each group (data not shown). Our data showed that HU induced a drastic increase of the sMLC2 phosphorylation $(+4.3$-fold, $\mathrm{p}<0.001)$, while it returned to control value in recovering soleus.

When the O-GlcNAc-bearing proteins were enriched before the Phos-tag ${ }^{\mathrm{TM}}$ electrophoresis, we detected only one band corresponding to the unphosphorylated form of sMLC2 (Fig.1b) while no signal was detected on the phosphorylated form of sMLC2. We quantified the signals obtained for each group, and demonstrated that O-GlcNAcylation level of sMLC2 strongly decreased after $\mathrm{HU}(-50.6 \%, \mathrm{p}<0.05)$. As was the case for phosphorylation, the reversibility was almost complete, since we did not measure a difference between $\mathrm{C}$ and $\mathrm{R}$ groups.

Taken together, these data argue in favour of an antagonism between phosphorylation and OGlcNAcylation on the regulatory MLC. Moreover, we did not characterize a sMLC2 form bearing concomitantly phosphate and GlcNAc moieties, suggesting that these both post-translational modifications could be mutually exclusive. 


\section{Phosphorylation and O-GIcNAcylation were mutually exclusive on SMLC2}

To support the idea that phosphorylation and O-GlcNAcylation did not occur simultaneously on sMLC2, we performed the enrichment of phosphorylated and/or O-GlcNAcylated proteins. One or two round(s) of chromatography(ies) was (were) performed in order to enrich the phosphoproteins, the OGlcNAcylated proteins and proteins bearing both post-translational modifications. In particular, the presence of sMLC2 in the eluates of the one-round or two-round chromatographies was investigated using western blot. The results were presented on figure 2 .

Lane 1 corresponded to phosphorylated sMLC2 while lane 2 corresponded to the OGlcNAcylated sMLC2. These signals were obtained after a one-round chromatography, on phosphoproteins enrichment chromatography or on WGA-chromatography respectively. Lane 3 corresponded to the non-phosphorylated but O-GlcNAcylated sMLC2, since the flow-through, i.e. the non-retained (NR) proteins from the phosphoproteins enrichment chromatography, was submitted to WGA-chromatography. It is noteworthy that similar signals were obtained for lanes 2 and 3. No signal was obtained for lane 4, suggesting that phosphorylated sMLC2 (eluted fraction from phosphoproteins enrichment chromatography) was not retained on WGA-chromatography. The same result was obtained when O-GlcNAcylated proteins (fraction eluted from WGA-chromatography) were passed through the phosphoproteins enrichment chromatography (lane 6 on Fig.2). Lastly, when the non-glycosylated proteins (non-retained fraction from WGA-chromatography) were passed through phosphoproteins enrichment chromatography, a signal was obtained for the non-glycosylated but phosphorylated sMLC2 (lane 5 on Fig.2, comparing with lane 1).

Taken together, all these data strongly support that phosphorylation and O-GlcNAcylation were mutually exclusive on SMLC2 since phosphorylation did not take place on O-GlcNAcylated sMLC2 and reciprocally.

\section{Enzymes expression was modulated on total proteins extract}

We quantified the expression of enzymes involved in the phosphorylation and the OGlcNAcylation of sMLC2 at the whole tissue proteins from control (C), atrophied (HU) and reloaded (R) soleus (figure 3). Fig.3a showed the pattern of total proteins from control soleus, while Fig.3b represented the variation of expression of these enzymes, compared with control group.

The enzymes of the O-GlcNAcylation process, i.e. OGT and OGA, were highly modulated during HU. Both enzymes presented a drastic decrease in their expression level in atrophied soleus ($67.1 \%, \mathrm{p}<0.01$, and $-92.2 \%, \mathrm{p}<0.001$, respectively). While OGT level returned to control values after reloading, the reversion for OGA expression was limited $(-65.3 \%, \mathrm{p}<0.001)$.

Among the phosphorylation/dephosphorylation enzymes, MLCK expression was not modulated in total proteins extract after HU or reloading. In contrast, PP1 was modulated in the same way as OGT since PP1 expression decreased in HU soleus $(-43.6 \%, \mathrm{p}<0.05)$, while the reversibility was complete in reloaded soleus. Surprisingly, the myosin phosphatase target MYPT2 was not modulated during HU, 
but its expression was 2.5 -fold higher in reloaded soleus $(\mathrm{p}<0.05)$.

\section{Enzymes expression was modulated on myofilament fraction}

We also analyzed the expression of these enzymes on myofilament-enriched fraction as presented in figure 4. Fig.4a corresponded to myofilament-enriched proteins, on which contractile proteins were easily identifiable as it was previously shown [20]. Data corresponding to the enzymes expression level in the myofilament fraction were presented on Fig.4b, comparing with the control group. It is noteworthy that we detected all the enzymes in the myofilament fraction, suggesting that each enzyme was located on the contractile apparatus. These data were corroborated with images obtained on confocal microscopy (see below).

The OGT expression decreased during HU $(-42.9 \%, \mathrm{p}<0.05)$ and remained at a similar level after the reloading period $(-38.5 \%, \mathrm{p}<0.05)$. The expression of OGA dramatically decreased on contractile apparatus $(-66.1 \%, \mathrm{p}<0.05)$. In contrast with OGT, the OGA expression partially reversed during reloading $(-34 \%$, n.s.).

MLCK, for which we observed a high heterogeneity of signals in HU and R groups, presented similar expression levels in all groups. Protein phosphatase PP1 decreased at the myofilament level ($48.5 \%, \mathrm{p}<0.05)$, but did not reverse since its expression remained $37.8 \%$ lower than control $(\mathrm{p}<0.05)$, as it was observed for OGT. MYPT2 expression significantly decreased after HU $(-43.7 \%$, p<0.05) and partially reversed after reloading $(-22.2 \%$, n.s.).

\section{The dynamic interplay between phosphorylation and O-GIcNAcylation involved a multienzymatic}

\section{complex}

The sMLC2 was post-translationally modified by phosphorylation or O-GlcNAcylation, the two modifications occurring solely on the protein as was demonstrated in the present study. To explain this dynamic and reversible interplay, we postulated that a multienzymatic complex could therefore associate two or more enzymes of the phosphorylation and/or the O-GlcNAcylation processes. To support this hypothesis, we performed several co-immunoprecipitation (co-IP) experiments to immunoprecipitate a protein of interest (i.e. OGT, OGA, PP1, MYPT2, MLCK or the target sMLC2), associated to their protein partners. For each co-IP, western blot (WB) analyses were then done to characterize the presence or the absence of each protein in the retained fraction of co-IP (containing the partners of the protein of interest).

As shown on figure 5 , we identified by western blot each protein in its proper co-IP, whereas we never detected a signal in the blank experiment (i.e. co-IP protocol without applying proteins sample), suggesting that the proteins of interest were correctly immunoprecipitated. For nearly all the experiments, signals were quite similar between $\mathrm{C}$ and $\mathrm{HU}$ groups, except for WB against MYPT2 for which signals were lower in control group comparing with the HU one.

Concerning the enzymes of the glycosylation/deglycosylation process, we observed a co-IP of 
OGT with OGA, PP1, MLCK, and sMLC2, as well as for reciprocal experiments except for co-IP sMLC2/WB OGT where a signal was obtained in blank experiment. For co-IP OGT/WB MYPT2, we observed a very slight signal in blank, but the result was validated by the reciprocal experiment. In the same manner, we showed the co-IP of OGA with OGT and PP1. Signal was particularly low in control soleus for MLCK; nevertheless, this data was confirmed by inverse experiment. Lastly, we clearly identified sMLC2 as co-interactant with OGT and OGA, but unfortunately, signals in blank were present in reciprocal experiment. Even if the signals in blank remain largely lower than those obtained in experiments, we estimated that these IP were insufficiently demonstrative to conclude about these interactions.

Concerning the enzymes of phosphorylation/dephosphorylation process, we showed an interaction between MYPT2 and PP1, as expected, as well as an interaction between both enzymes and the target SMLC2. We also noted a co-IP of MLC2 with MLCK. We were not able to make a conclusion regarding the interaction between MLCK and PP1, nor MYPT2 and MLCK, because the signals obtained were weak, or since there was no clear correlation between the two reciprocal experiments. The experimental protocol of binding and washes could be too astringent, and as such could mask the existence of some protein-protein interactions, particularly weak interactions. When MLCK, PP1 or MYPT2 were immunoprecipitated, OGT and OGA were found in the retained fraction, as was shown just above.

To conclude, we demonstrated that glycosylation/deglycosylation and phosphorylation/ dephosphorylation enzymes were associated within a multienzymatic complex, even if direct or indirect partners were unknown. Interestingly, this multienzymatic complex was showed to interact itself with the target sMLC2. All of the interactions were also observed in atrophied muscle, the signals being sometimes different from control soleus. However, the difference in the intensity of the signals could also be explained by differential enzymes expression.

\section{Enzymes of phosphorylation and O-GlcNAcylation processes were colocalized to sarcomere}

To confirm the effective interaction between the enzymes, we performed immunofluorescence analysis to get their colocalization degree two at a time. Longitudinal slides of control and atrophied soleus were double stained using the same antibodies as those used in co-IP/WB approach; images were acquired using confocal microscopy. To determine the degree of overlap between the two channels, Manders' and Pearson's coefficients were determined for nine double staining, chosen according to the compatibility of primary antibodies. The Manders' coefficient indicated an actual overlap of the signals, and was expressed from 0 to 1.0 (0.9 implies that $90 \%$ of both channels colocalize) [51]. The Pearson's coefficient described the correlation of the intensity distribution between channels. Values were expressed from -1.0 to $1.0,0$ indicating that no significant correlation exists, whereas -1.0 value indicates a complete negative correlation [51]. Data were expressed in Table I, and representative images of colocalization were presented in Online Resource 1. Negative control experiments consisting in the 
incubation of slides with secondary antibodies alone were done; even when overexposed, we did not detect any signal (data not shown).

Firstly, we detected all the enzymes of interest on the sarcomere, as seen in the western blot analysis performed on myofilament-enriched fraction. Secondly, we measured the higher colocalization coefficients between OGT/MLCK and OGA/MLCK (around 90\% for Manders' and 0.75 for Pearson's coefficients). Slightly lower coefficient values (Pearson's coefficient higher than 0.6) were measured for OGT/PP1, MYPT2/MLCK, OGT/OGA, and MYPT2/OGA. Finally, we measured Pearson's coefficient around 0.4 for PP1/OGA, PP1/MLCK and MYPT2/PP1. Interestingly, when we compared values between control and atrophied soleus, we measured an increase in the OGA/MLCK colocalization in HU soleus (from $0.751 \pm 0.021$ to $0.839 \pm 0.016$ for Pearson's coefficient, $\mathrm{p}<0.01$ ). The representative change of colocalization between these two enzymes was presented on figure 6 .

In conclusion, using two independent methods, we demonstrated a colocalization (that might involve direct or indirect interactions) between enzymes of glycosylation/deglycosylation and phosphorylation/dephosphorylation processes. These results corroborated those obtained with the coIP/WB experiments, and reinforced the colocalization of MLCK, PP1 and MYPT2. All together, these data argue in favour of a multienzymatic complex. We also showed that the colocalization between OGA and MLCK increased during HU. It is noteworthy that the location of each enzyme was coordinated to the striation of the sarcomere.

\section{The multienzymatic complex was preferentially located at the Z-disk}

As previously mentioned, we detected OGT, OGA, PP1, MYPT2 and MLCK on the myofilament fraction, and observed that these enzymes presented an organisation particularly well structured, with a remarkable striated aspect. So, we attempted to localize each of these enzymes more precisely on the contractile apparatus.

We performed a double staining of each of the enzymes with actinin, a marker of the Z-disk. To better localize the enzymes, we also made the image acquisition on light microscopy. The DIC (Differential Interference Contrast) images and corresponding fluorescence images were acquired simultaneously. The double staining of OGT with actinin, as well as the DIC image, were presented on Fig.7A. On DIC image, the white line located between two dark bands was completely colocalized with the actinin staining; we assigned this white line to Z-disk. The two dark bands across this white line were assigned to I-bands and the larger light band was assigned to the A-band. We also visualized the OGT (in green on Fig.7A), and showed that OGT localized at the Z-disk and at the dark bands corresponding to the I-band.

The same analysis was performed for OGA, MLCK, PP1 and MYPT2; immunofluorescence images corresponding to double staining of the enzymes with actinin were presented in Fig.7B. Interestingly, OGA and MLCK presented the same localization than OGT. The repartition of MLCK and OGA, and to a lesser extent OGT, also appeared at the A-band even if staining was much more 
diffuse and less marked than Z-disk and I-band. In contrast, PP1 and MYPT2 seemed to be preferentially located at the Z-disk, with a uniform distribution around the Z-disk

In view of the localization of the different enzymes along the contractile apparatus, we proposed that the multienzymatic complex was preferentially localized at the Z-disk. Of course, each of these enzymes, especially OGT and OGA, could also be localized independently at the I-band, where they could glycosylated and deglycosylated other substrates than sMLC2.

\section{DISCUSSION}

In the present study we have focused on the variation of O-GlcNAcylation on the slow isoform of regulatory myosin light chain (sMLC2), a protein that could be involved in the contractile dysfunction observed in atrophied muscle. We showed in this study that phosphorylation and O-GlcNAcylation of sMLC2 were modulated during functional atrophy induced by hindlimb unloading, and reversed during reloading. Phosphorylation and O-GlcNAcylation were mutually exclusive on SMLC2, and varied in opposite ways according to loading conditions. This interplay between both translational modifications involved the modulation of expression of each enzyme at the whole tissue level and/or at the myofilament. These enzymes were included within a multienzymatic complex; interestingly, each of these enzymes was localized on the contractile apparatus, preferentially at the Z-disk and at the I-band of the sarcomere.

The most important finding of this paper was the dynamic interplay between phosphorylation and O-GlcNAcylation on sMLC2 during hindlimb unloading and recovery. Using Phos-Tag electrophoresis, we quantified the variation of O-GlcNAcylation on the unphosphorylated and phosphorylated forms of MLC2s. Although the up-regulation of phosphorylation on sMLC2 was previously described [2], this study showed a down-regulation of the O-GlcNAcylation level during hindlimb unloading. The variation of O-GlcNAcylation occurred only on the unphosphorylated sMLC2, as was not detected an isoform bearing concomitantly the two post-translational modifications. Interestingly, this antagonism between phosphorylation and glycosylation completely reversed when animal were reloaded, suggesting a dynamic regulation dependent of muscle loading. This antagonism could involve the same site. Indeed, serine 14 was identified to be phosphorylated [1, 42] while the only identified O-GlcNAc site on cardiac MLC2 (also known as the slow skeletal muscle MLC2) corresponds to serine 14 [37]. Taken together, all of these elements suggested a key role of the phosphorylation/OGlcNAcylation interplay in the fine regulation of sMLC2 functional activity.

While several works supported that phosphorylation of MLC2 was strongly associated with an increase of calcium sensitivity [24, 29, 36, 43, 44], aging or reduced physical activity were associated with an increase of phosphorylation on MLC2 whereas the calcium sensitivity decreased [2,13]. As a 
consequence, the decrease in calcium sensitivity occurring during $\mathrm{HU}$ could not result from phosphorylation variation, but rather may involve another type of regulation. A few years ago, we investigated the role of O-GlcNAcylation in the modulation of contractile properties. We demonstrated that incubation of soleus skinned fibers in a solution of free N-acetyl-D-glucosamine lead to a totally reversible decrease in calcium sensitivity and affinity [20, 37]. Interestingly, this effect was also observed in cardiac muscle [37] and in human skeletal muscle fibers [8]. Taken together, these data strongly supported that O-GlcNAcylation could modulate the calcium activation properties of striated muscles. Recently, we have shown that the increase of O-GlcNAcylation level on soleus organo-culture lead to an increase of calcium affinity [7]. We attempted to identify contractile proteins presenting an increase of their O-GlcNAcylation level; interestingly, the only slow protein proposed to be involved in the increase in calcium affinity was the sMLC2. However, the existence of a potential interplay with phosphorylation of MLC2 has never been examined to date. To take into account the link between OGlcNAcylation and calcium sensitivity, involving potentially MLC2, and in view of our findings in the present study, we could hypothesize that the decrease of O-GlcNAcylation on SMLC2 could be partly involved in the contractile dysfunction associated with $\mathrm{HU}$, more particularly the decrease in calcium sensitivity, whereas phosphorylation may rather be a marker of the phenotype transition $[2,38,41]$.

To explain the modulation of sMLC2 glycosylation, we quantified the expression of the enzymes involved in the glycosylation/deglycosylation process. Our results indicated that HU induced a decrease of OGT expression at the whole proteome level which corroborated the decrease of OGT activity during HU as it was previously measured [9]. While we showed that OGT was localized to contractile apparatus, this decrease of OGT expression was also observed at the myofilament fraction. This variation of expression was reversible, which corroborates the variation of O-GlcNAc level on sMLC2. Interestingly, OGT expression seemed to be load-dependent since its expression was higher when rats were reloaded. Surprisingly, we detected the same modulation for OGA expression while we previously measured an increase of OGA activity. To explain this discrepancy, we considered the specificity of the polyclonal antibody used in this study, which recognizes the full-length MGEA5. The OGA is constituted of two domains: the O-GlcNAcase and the HAT domains. It was demonstrated that MGEA5 could be cleaved between the two domains without altering the O-GlcNAcase activity [3]. We could postulate that MGEA5 antibody loses its recognition capacity as a consequence of the cutting out of the enzyme, leading so to a drastic decrease in the expression level of OGA, independently of the modulation of OGA activity.

We also investigated the expression of the kinase/phosphatase involved in the modulation of phosphorylation status of sMLC2. The increase of phosphorylation on SMLC2 could not be explained through the MLCK expression, but rather by the decrease of expression and/or activity of myosin phosphatase. Indeed, the variations of expression of PP1 and MYPT2, which confers the specificity of PP1 toward the sMLC2, were closely linked to variation of phosphorylation on sMLC2 at the myofilament fraction; interestingly, these variations were parallel to OGT expression, suggesting that 
all of these enzymes could be submitted to the same regulation pathway.

Another important finding in this paper was the characterization of a multienzymatic and sarcomeric complex resulting in the fine modulation of the phosphorylation and O-GlcNAcylation levels on sMLC2. We demonstrated that OGT, OGA, PP1, MLCK and MYPT2 were associated within the same complex and also with their target sMLC2. While some papers previously described an interaction between OGT and phosphatases [5, 48], leading so to a concomitant increase of O-GlcNAcylation pattern and a decrease of phosphorylation level, we showed in the present study that an interaction between OGA and kinases also occurred, since OGA interacted with MLCK. In the same way, multienzymatic complex associating OGT/OGA and kinase/phosphatase couples was described in the modulation of cell cycle [40]. The enzyme interactions in the complex could be modulated during HU since we described a differential colocalization of OGA with MLCK, which argue in favour of the phosphorylation associated to the deglycosylation of MLC2. Interestingly, immunofluorescence images revealed that each of these enzymes presented a similar striated organization.

By immunofluorescence assay, we assessed the localization of these enzymes along the sarcomeric apparatus. Our data clearly showed that OGT, OGA and MLCK strongly colocalized with the Z-disk and the I-band, whereas PP1 and MYPT2 were preferentially located around the Z-disk. MYPT2 was previously described to be located at, or close to, the Z-line, the A-band and mitochondria in heart, although the location to A-band and in mitochondria was irregular [35]. A subproteomic analysis of cardiac myofilament revealed that signalling kinases (such as PP2A) or phosphatases (such as MYPT1 and MYPT2), were located to myofilament, more particularly at the Z-disk for MYPT1/2 [50]. Initially considered as a passive constituent of the sarcomere, the Z-disk is nowadays considered as a nodal point for anchoring cytoskeletal proteins, channels, apoptotic proteins, enzymes and signalling molecule active in the cytoplasm and in nucleus [12, 39]. Moreover, the sarcomeric localization of proteins is not always confined to a single sarcomeric band; indeed, proteins could relocalize from Zdisk to A-band according to physiological demands [39, 50]. In skeletal and cardiac muscle diseases, the Z-disk is often remodelled and could be considered as a link between structural aspect and maladjustment of muscle [25]. This is the first report of the localization of OGT and OGA on this particular structure, which could finally explain why so many contractile and structural proteins were O-GlcNAc modified. Moreover, the colocalization of O-GlcNAcylation enzymes with MLCK and myosin phosphatase in a complex at the vicinity of the target could explain the dynamism of phosphorylation and O-GlcNAcylation variation on SMLC2.

To conclude, we demonstrated a dynamic interplay, dependent on the loading condition, between phosphorylation and O-GlcNAcylation on sMLC2, a regulatory protein involved in the modulation of contractile properties of skeletal muscle. Both post-translational modifications were mutually exclusive. Interestingly, the variation of O-GlcNAcylation was correlated with contractile dysfunction associated with hindlimb unloading. We also showed that the fine modulation of phosphorylation and O-GlcNAcylation on sMLC2 involved a multienzymatic complex localized on 
contractile apparatus, more precisely at the Z-disk which correspond to a nodal point of signalling in skeletal muscle. It will be necessary in the future to investigate the modulation of O-GlcNAcylation on sMLC2 as well as the dynamic of the multienzymatic complex in muscle dysfunction such as sedentarity, sarcopenia or type II diabetes. The characterization of the role of O-GlcNAcylation in the modulation of contractile properties should be extended to other regulatory proteins, since its involvement in activity of skeletal muscle is undoubtedly underappreciated.

\section{ACKNOWLEDGMENTS}

This work was supported by grants from the Association Française contre les Myopathies (AFM, $\mathrm{n}^{\circ} 13890$ ) and the Centre National d'Etudes Spatiales (CNES, 4800000658). We thank the BioImaging Center of Lille at the University of Lille 1 for immunofluorescence acquisitions. We also thank Dr. Christian Slomianny for his helpful advices, Laetitia Cochon for technical help and Dr Alan McCall for English editing.

\section{ETHICAL STANDARDS}

All procedures described above received authorization from the Agricultural and Forest Ministry and the National Education Ministry (veterinary service of health and animal protection, authorization CEEA AF 12/2010).

\section{CONFLICT OF INTEREST}

The authors declare that they have no conflict of interest. 


\section{Reference List}

[1] Blumenthal DK and Stull JT (1980) Activation of skeletal muscle myosin light chain kinase by calcium(2+) and calmodulin. Biochemistry 19:5608-5614.

[2] Bozzo C, Stevens L, Toniolo L, Mounier Y, Reggiani C (2003) Increased phosphorylation of myosin light chain associated with slow-to-fast transition in rat soleus. Am J Physiol Cell Physiol 285:C575-C583.

[3] Butkinaree C, Cheung WD, Park S, Park K, Barber M, Hart GW (2008) Characterization of beta$\mathrm{N}$-acetylglucosaminidase cleavage by caspase-3 during apoptosis. J Biol Chem 283:23557-23566.

[4] Cheung WD and Hart GW (2008) AMP-activated protein kinase and p38 MAPK activate OGlcNAcylation of neuronal proteins during glucose deprivation. J Biol Chem 283:13009-13020.

[5] Cheung WD, Sakabe K, Housley MP, Dias WB, Hart GW (2008) O-linked beta-Nacetylglucosaminyltransferase substrate specificity is regulated by myosin phosphatase targeting and other interacting proteins. J Biol Chem 283:33935-33941.

[6] Cieniewski-Bernard C, Bastide B, Lefebvre T, Lemoine J, Mounier Y, Michalski JC (2004) Identification of O-linked $\mathrm{N}$-acetylglucosamine proteins in rat skeletal muscle using twodimensional gel electrophoresis and mass spectrometry. Mol Cell Proteomics 3:577-585.

[7] Cieniewski-Bernard C, Montel V, Berthoin S, Bastide B (2012) Increasing O-GlcNAcylation Level on Organ Culture of Soleus Modulates the Calcium Activation Parameters of Muscle Fibers. PLoS One 7:e48218.

[8] Cieniewski-Bernard C, Montel V, Stevens L, Bastide B (2009) O-GlcNAcylation, an original modulator of contractile activity in striated muscle. J Muscle Res Cell Motil 30:281-287.

[9] Cieniewski-Bernard C, Mounier Y, Michalski JC, Bastide B (2006) O-GlcNAc level variations are associated with the development of skeletal muscle atrophy. J Appl Physiol 100:1499-1505.

[10] Copeland RJ, Bullen JW, Hart GW (2008) Cross-talk between GlcNAcylation and phosphorylation: roles in insulin resistance and glucose toxicity. Am J Physiol Endocrinol Metab 295:E17-E28.

[11] Dong DL and Hart GW (1994) Purification and characterization of an O-GlcNAc selective Nacetyl-beta-D-glucosaminidase from rat spleen cytosol. J Biol Chem 269:19321-19330.

[12] Frank D, Kuhn C, Katus HA, Frey N (2006) The sarcomeric Z-disc: a nodal point in signalling and disease. J Mol Med (Berl) 84:446-468.

[13] Gannon J, Staunton L, O'Connell K, Doran P, Ohlendieck K (2008) Phosphoproteomic analysis of aged skeletal muscle. Int J Mol Med 22:33-42.

[14] Gao Y, Wells L, Comer FI, Parker GJ, Hart GW (2001) Dynamic O-glycosylation of nuclear and cytosolic proteins: cloning and characterization of a neutral, cytosolic beta-Nacetylglucosaminidase from human brain. J Biol Chem 276:9838-9845.

[15] Haltiwanger RS, Blomberg MA, Hart GW (1992) Glycosylation of nuclear and cytoplasmic proteins. Purification and characterization of a uridine diphospho-Nacetylglucosamine:polypeptide beta-N-acetylglucosaminyltransferase. J Biol Chem 267:90059013. 
[16] Haltiwanger RS, Holt GD, Hart GW (1990) Enzymatic addition of O-GlcNAc to nuclear and cytoplasmic proteins. Identification of a uridine diphospho-N-acetylglucosamine:peptide beta-Nacetylglucosaminyltransferase. J Biol Chem 265:2563-2568.

[17] Hanover JA, Yu S, Lubas WB, Shin SH, Ragano-Caracciola M, Kochran J, Love DC (2003) Mitochondrial and nucleocytoplasmic isoforms of O-linked GlcNAc transferase encoded by a single mammalian gene. Arch Biochem Biophys 409:287-297.

[18] Hart GW, Housley MP, Slawson C (2007) Cycling of O-linked beta-N-acetylglucosamine on nucleocytoplasmic proteins. Nature 446:1017-1022.

[19] Hart GW, Slawson C, Ramirez-Correa G, Lagerlof O (2011) Cross talk between O-GlcNAcylation and phosphorylation: roles in signaling, transcription, and chronic disease. Annu Rev Biochem $80: 825-858$.

[20] Hedou J, Cieniewski-Bernard C, Leroy Y, Michalski JC, Mounier Y, Bastide B (2007) O-linked $\mathrm{N}$-acetylglucosaminylation is involved in the $\mathrm{Ca} 2+$ activation properties of rat skeletal muscle. $\mathrm{J}$ Biol Chem 282:10360-10369.

[21] Huang P, Ho SR, Wang K, Roessler BC, Zhang F, Hu Y, Bowe DB, Kudlow JE, Paterson AJ (2011) Muscle-specific overexpression of NCOATGK, splice variant of O-GlcNAcase, induces skeletal muscle atrophy. Am J Physiol Cell Physiol 300:C456-C465.

[22] Issad T, Masson E, Pagesy P (2010) O-GlcNAc modification, insulin signaling and diabetic complications. Diabetes Metab 36:423-435.

[23] Iyer SP and Hart GW (2003) Roles of the tetratricopeptide repeat domain in O-GlcNAc transferase targeting and protein substrate specificity. J Biol Chem 278:24608-24616.

[24] Kamm KE and Stull JT (2011) Signaling to myosin regulatory light chain in sarcomeres. J Biol Chem 286:9941-9947.

[25] Knoll R, Buyandelger B, Lab M (2011) The sarcomeric Z-disc and Z-discopathies. J Biomed Biotechnol 2011:569628.

[26] Lazarus BD, Love DC, Hanover JA (2009) O-GlcNAc cycling: implications for neurodegenerative disorders. Int J Biochem Cell Biol 41:2134-2146.

[27] Lefebvre T, Dehennaut V, Guinez C, Olivier S, Drougat L, Mir AM, Mortuaire M, VercoutterEdouart AS, Michalski JC (2010) Dysregulation of the nutrient/stress sensor O-GlcNAcylation is involved in the etiology of cardiovascular disorders, type-2 diabetes and Alzheimer's disease. Biochim Biophys Acta 1800:67-79.

[28] Lunde IG, Aronsen JM, Kvaloy H, Qvigstad E, Sjaastad I, Tonnessen T, Christensen G, GronningWang LM, Carlson CR (2012) Cardiac O-GlcNAc signaling is increased in hypertrophy and heart failure. Physiol Genomics 44:162-172.

[29] MacIntosh BR (2003) Role of calcium sensitivity modulation in skeletal muscle performance. News Physiol Sci 18:222-225.

[30] Marsh SA, Powell PC, Dell'italia LJ, Chatham JC (2013) Cardiac O-GlcNAcylation blunts autophagic signaling in the diabetic heart. Life Sci 92:648-656.

[31] Moorhead G, Johnson D, Morrice N, Cohen P (1998) The major myosin phosphatase in skeletal muscle is a complex between the beta-isoform of protein phosphatase 1 and the MYPT2 gene product. FEBS Lett 438:141-144. 
[32] Morey ER, Sabelman EE, Turner RT, Baylink DJ (1979) A new rat model simulating some aspects of space flight. Physiologist 22:S23-S24.

[33] Morey-Holton ER and Globus RK (2002) Hindlimb unloading rodent model: technical aspects. J Appl Physiol 92:1367-1377.

[34] Nakamura S, Nakano S, Nishii M, Kaneko S, Kusaka H (2012) Localization of O-GlcNAcmodified proteins in neuromuscular diseases. Med Mol Morphol 45:86-90.

[35] Okamoto R, Kato T, Mizoguchi A, Takahashi N, Nakakuki T, Mizutani H, Isaka N, ImanakaYoshida K, Kaibuchi K, Lu Z, Mabuchi K, Tao T, Hartshorne DJ, Nakano T, Ito M (2006) Characterization and function of MYPT2, a target subunit of myosin phosphatase in heart. Cell Signal 18:1408-1416.

[36] Persechini A, Stull JT, Cooke R (1985) The effect of myosin phosphorylation on the contractile properties of skinned rabbit skeletal muscle fibers. J Biol Chem 260:7951-7954.

[37] Ramirez-Correa GA, Jin W, Wang Z, Zhong X, Gao WD, Dias WB, Vecoli C, Hart GW, Murphy AM (2008) O-linked GlcNAc modification of cardiac myofilament proteins: a novel regulator of myocardial contractile function. Circ Res 103:1354-1358.

[38] Ricart-Firinga C, Stevens L, Canu MH, Nemirovskaya TL, Mounier Y (2000) Effects of beta(2)agonist clenbuterol on biochemical and contractile properties of unloaded soleus fibers of rat. Am J Physiol Cell Physiol 278:C582-C588.

[39] Sanger JM and Sanger JW (2008) The dynamic Z bands of striated muscle cells. Sci Signal 1:e37.

[40] Slawson C, Lakshmanan T, Knapp S, Hart GW (2008) A mitotic GlcNAcylation/phosphorylation signaling complex alters the posttranslational state of the cytoskeletal protein vimentin. Mol Biol Cell 19:4130-4140.

[41] Stevens L, Firinga C, Gohlsch B, Bastide B, Mounier Y, Pette D (2000) Effects of unweighting and clenbuterol on myosin light and heavy chains in fast and slow muscles of rat. Am J Physiol Cell Physiol 279:C1558-C1563.

[42] Stull JT, Kamm KE, Vandenboom R (2011) Myosin light chain kinase and the role of myosin light chain phosphorylation in skeletal muscle. Arch Biochem Biophys 510:120-128.

[43] Sweeney HL, Bowman BF, Stull JT (1993) Myosin light chain phosphorylation in vertebrate striated muscle: regulation and function. Am J Physiol 264:C1085-C1095.

[44] Szczesna D, Zhao J, Jones M, Zhi G, Stull J, Potter JD (2002) Phosphorylation of the regulatory light chains of myosin affects $\mathrm{Ca} 2+$ sensitivity of skeletal muscle contraction. J Appl Physiol 92:1661-1670.

[45] Takashima S (2009) Phosphorylation of myosin regulatory light chain by myosin light chain kinase, and muscle contraction. Circ J 73:208-213.

[46] Torres CR and Hart GW (1984) Topography and polypeptide distribution of terminal Nacetylglucosamine residues on the surfaces of intact lymphocytes. Evidence for O-linked GlcNAc. J Biol Chem 259:3308-3317.

[47] Wells L, Gao Y, Mahoney JA, Vosseller K, Chen C, Rosen A, Hart GW (2002) Dynamic Oglycosylation of nuclear and cytosolic proteins: further characterization of the nucleocytoplasmic beta-N-acetylglucosaminidase, O-GlcNAcase. J Biol Chem 277:1755-1761. 
[48] Wells L, Kreppel LK, Comer FI, Wadzinski BE, Hart GW (2004) O-GlcNAc transferase is in a functional complex with protein phosphatase 1 catalytic subunits. J Biol Chem 279:38466-38470.

[49] Whisenhunt TR, Yang X, Bowe DB, Paterson AJ, Van Tine BA, Kudlow JE (2006) Disrupting the enzyme complex regulating O-GlcNAcylation blocks signaling and development. Glycobiology 16:551-563.

[50] Yin X, Cuello F, Mayr U, Hao Z, Hornshaw M, Ehler E, Avkiran M, Mayr M (2010) Proteomics analysis of the cardiac myofilament subproteome reveals dynamic alterations in phosphatase subunit distribution. Mol Cell Proteomics 9:497-509.

[51] Zinchuk V and Grossenbacher-Zinchuk O (2009) Recent advances in quantitative colocalization analysis: focus on neuroscience. Prog Histochem Cytochem 44:125-172. 


\section{Figures legend}

Fig.1 Phosphorylation/O-GIcNAcylation interplay on sMLC2. Myofilament proteins were separated using Phos-Tag affinity electrophoresis, and revealed using anti-sMLC2 antibody (a) or the same protocol was applied after immunoprecipitation of O-GlcNAc bearing proteins (b). Representative signals obtained for $\mathrm{C}, \mathrm{HU}$ and R soleus were presented above histograms. As indicated on blot images, the mono-phosphorylated sMLC2 was retarded comparing with the non-phosphorylated sMLC2. Histograms corresponded to densitometric analysis of signals, and represented the semi-quantitative variation of phosphorylation level (a) or O-GlcNAcylation level (b) on sMLC2. Significant differences between $\mathrm{HU}$ and other groups were referenced as follows: * $\mathrm{p}<0.05 ; * * * \mathrm{p}<0.001$.

Fig.2 Characterization of the phosphorylated and/or glycosylated status of sMLC2. Affinity chromatographies were performed to enrich the phosphoproteins, the O-GlcNAcylated proteins or proteins bearing both post-translational modifications. The markers in the table indicated if one-round or two-rounds of chromatography(ies) was (were) performed. NR and E corresponded to the nonretained fraction or the eluted fraction respectively at the end of the first-round chromatography. Both fractions were treated in parallel for a second round of chromatography in order to retained proteins bearing a phosphate and O-GlcNAc moieties. The presence of sMLC2 in the eluates of the one-round or two-round chromatographies was investigated using western blot as presented at the bottom of the figure.

Fig.3 Variation of expression of enzymes involved in glycosylation/deglycosylation and phosphorylation/dephosphorylation processes on SMLC2 on total proteins extracts from $\mathrm{C}, \mathrm{HU}$ and R groups. (a) Total proteins from control soleus were separated on 12.5\% SDS-PAGE and revealed by Sypro Ruby staining. (b) Fifty micrograms of total proteins extract were separated on $7.5 \%$ or $15 \%$ SDS-PAGE, and analyzed by western blot to detect OGT, OGA, MLCK, PP1 and MYPT2 enzymes. Densitometric analysis was performed to quantify the variation of each signal. Significant differences between each group were referenced as follows: $* \mathrm{p}<0.05$; ** $\mathrm{p}<0.01 ; * * * \mathrm{p}<0.001$.

Fig.4 Variation of expression of enzymes involved in glycosylation/deglycosylation and phosphorylation/dephosphorylation processes on sMLC2 on myofilament proteins extracts from C, HU and R groups. (a) Myofilament proteins from control soleus were separated on 12.5\% SDSPAGE and revealed by Sypro Ruby staining. (b) Fifty micrograms of myofilament proteins were separated on $7.5 \%$ or $15 \%$ SDS-PAGE, and analyzed by western blot to detect OGT, OGA, MLCK, PP1 and MYPT2 enzymes. Densitometric analysis was performed to quantify the variation of each signal. Significant differences between each group were referenced as follows: $* \mathrm{p}<0.05$.

Fig.5 Characterization of a multienzymatic complex using a co-immunoprecipitation approach followed by western blot analysis. On each square were represented signals obtained after co- 
immunoprecipitation (co-IP) of each enzyme of interest, followed by an electrophoretic separation and an immunodetection of the different enzymes. Five hundred micrograms of whole proteins extracts were used for co-IP. The first lane (B) corresponded to experimental blank (i.e. the IP experiment performed without applying proteins samples). The second lane (C) corresponded to signals obtained in control soleus, while the third lane (HU) represented signals obtained in HU samples. Data presented were representative of three independent experiments.

Fig.6 Change of colocalization degree between MLCK and OGA consecutively to hindlimb unloading. Longitudinal slides of soleus muscle were double stained using antibodies directed against MLCK and OGA. Images were acquired using confocal microscopy (x40). The images and corresponding merge were presented from control ( $\mathrm{C}$, at the top) and atrophied (HU, at the bottom) soleus. Scale corresponded to $10 \mu \mathrm{m}$.

Fig.7 Localization of enzymes along the contractile apparatus. Longitudinal slides of soleus muscle were double stained using antibodies against OGT, OGA, MLCK, PP1 or MLCK, with actinin, a marker of Z-disk. (a) A double staining of OGT and actinin was done; the DIC (Differential Interference Contrast) image and corresponding fluorescence images were acquired simultaneously. On the top of the figure were presented the two channels corresponding to OGT and actinin respectively, and between those two the corresponding DIC image. Just below were presented the merged images between DIC and OGT or actinin respectively. At the bottom of this panel was presented the magnified region corresponding to the white box on DIC image, where were localized the Z-disk, the I-band and the Aband of the sarcomere. (b) Representative immunofluorescence images corresponding to double staining of actinin with OGT, OGA, MLCK, PP1 and MYPT2 were presented with the merge image. Scale corresponded to $5 \mu \mathrm{m}$. 
a sMLC2 phosphorylation b sMLC2 O-GlcNAcylation
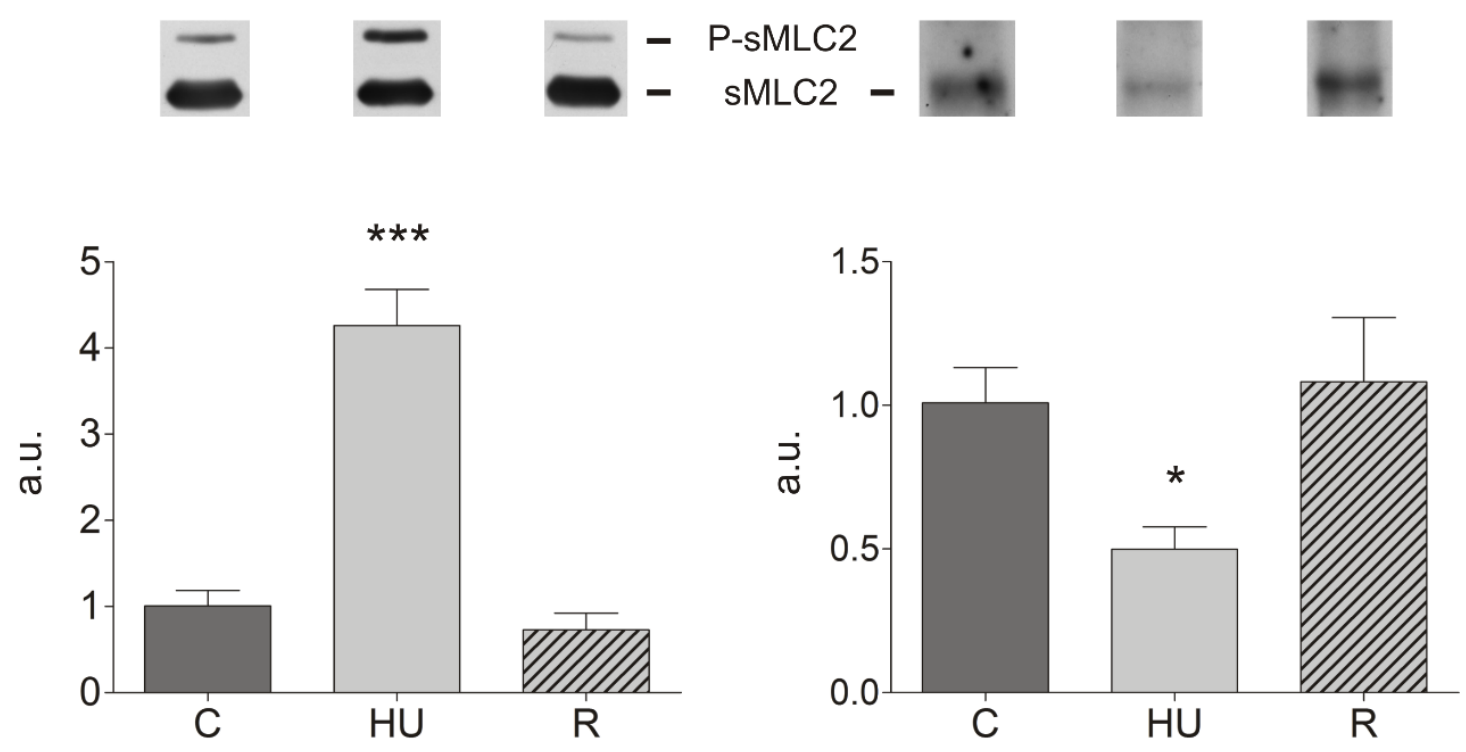

Figure 1 


\begin{tabular}{|c|c|c|c|c|c|c|c|}
\hline & & 1 & 2 & 3 & 4 & 5 & 6 \\
\hline \multirow{3}{*}{ 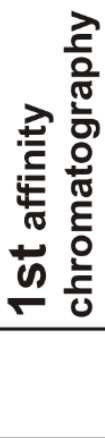 } & $\begin{array}{l}\text { phosphoproteins } \\
\text { enrichment }\end{array}$ & $X$ & & $X$ & $X$ & & \\
\hline & $\begin{array}{l}\text { O-GIcNAc proteins } \\
\text { enrichment }\end{array}$ & & $X$ & & & $X$ & $X$ \\
\hline & $\begin{array}{l}\text { selected fraction for } \\
\text { 2nd chomatography }\end{array}$ & & & NR & $E$ & NR & $E$ \\
\hline \multirow{3}{*}{ 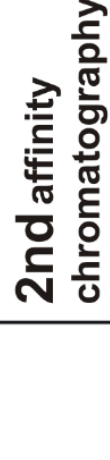 } & $\begin{array}{l}\text { phosphoproteins } \\
\text { enrichment }\end{array}$ & & & & & $X$ & $X$ \\
\hline & $\begin{array}{l}\text { O-GIcNAc proteins } \\
\text { enrichment }\end{array}$ & & & $X$ & $X$ & & \\
\hline & $\begin{array}{l}\text { sMLC2 expression } \\
\text { in eluted fractions }\end{array}$ & & & & & & \\
\hline
\end{tabular}

Figure 2 
a

$\mathrm{kDa}$

${ }_{150}^{250}=$

$100-$

$75-$

$50-$

$37-$

$25-$

$20-$

$15-$ b

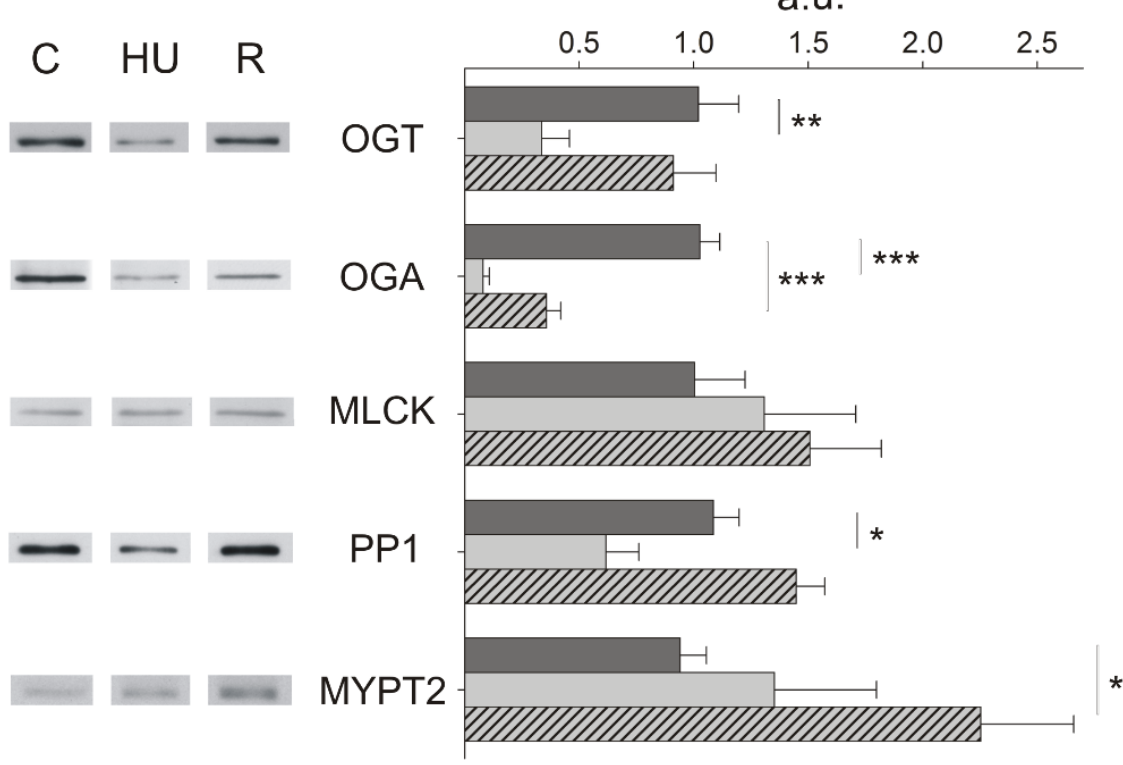

$\square \mathrm{C} \quad \square \mathrm{HU} \quad \mathrm{V} \mathrm{R}$

Figure 3 
a

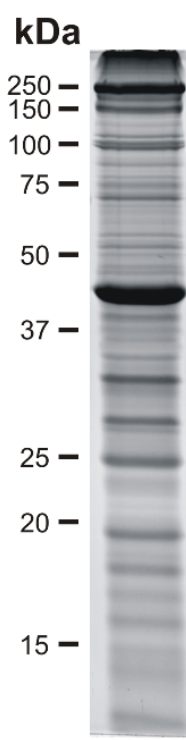

b

C $\mathrm{HU} R$

$\because-$ OGT

$-\quad$ OGA
$-\square=$ MLCK

$-\quad-\quad \mathrm{PP} 1$

$--1-\quad$ MYPT2 a.u.
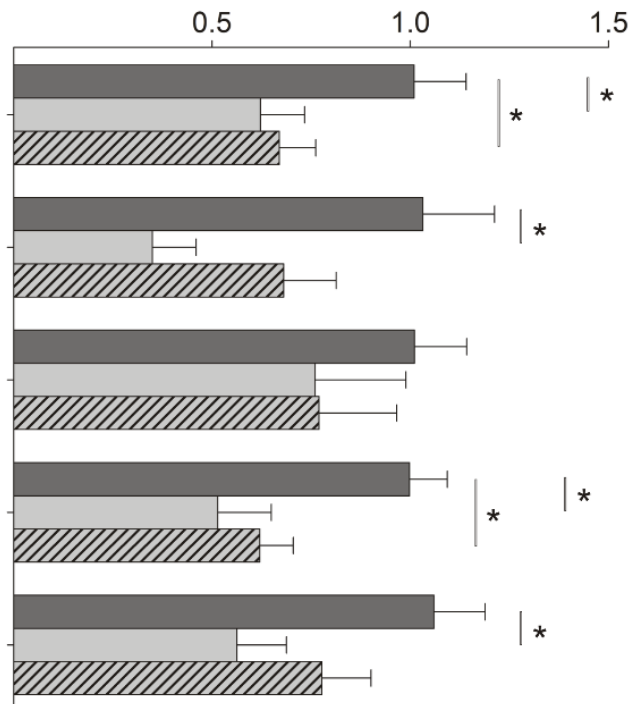

$\square \mathrm{C} \quad \square \mathrm{HU} \quad \mathbb{Z} \mathrm{R}$

Figure 4 


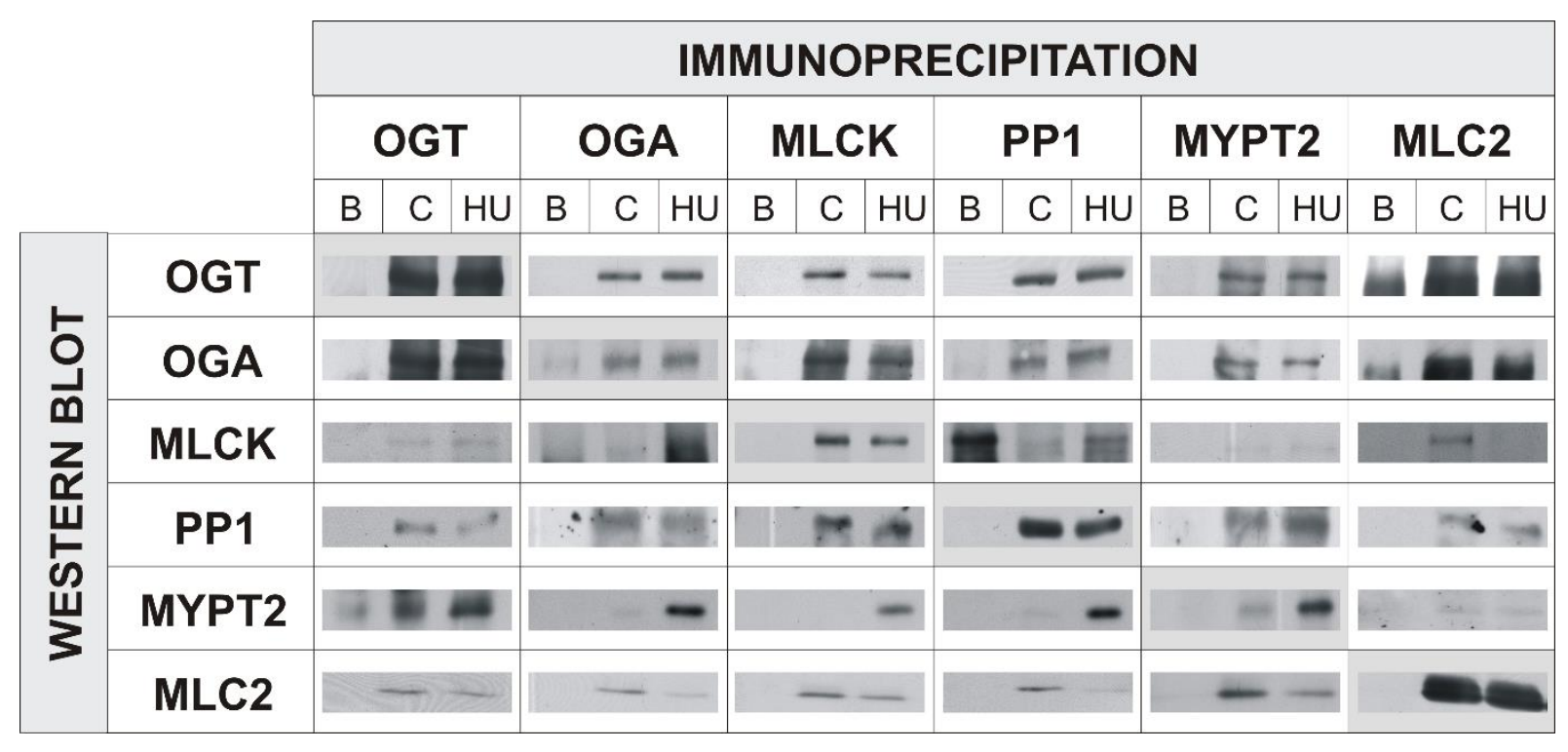

Figure 5 


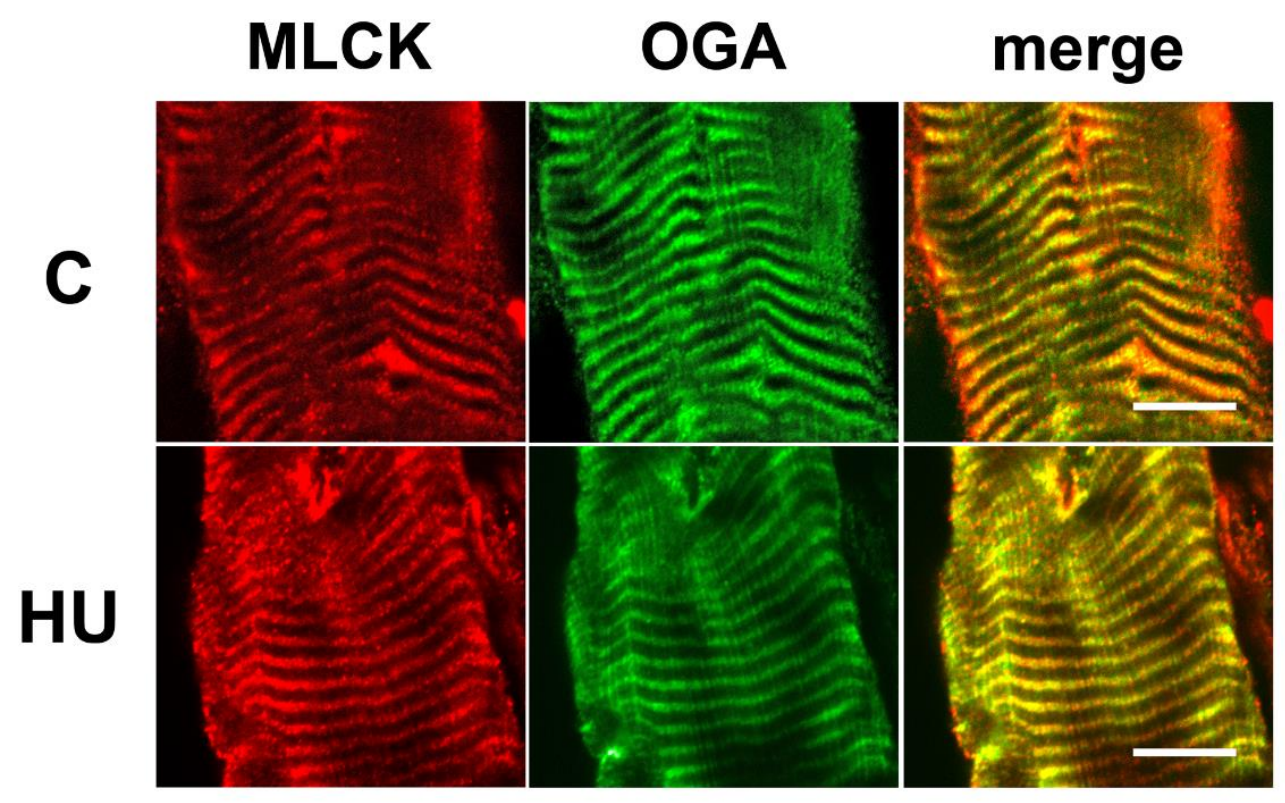

Figure 6 


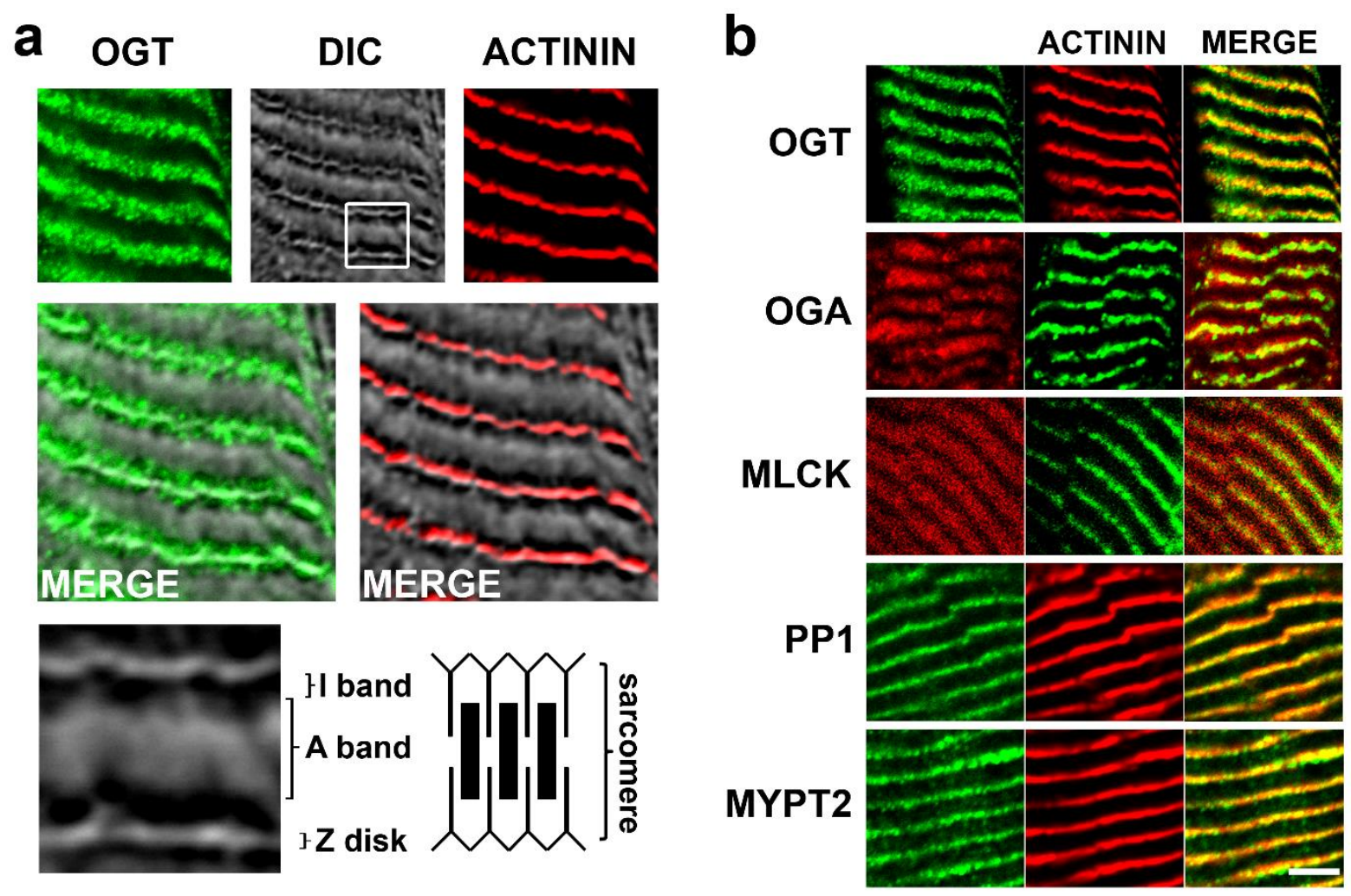

Figure 7 